\title{
Utilization of renewable energy resources
}

\author{
Vishnu vardhan.ch ${ }^{1}$ \\ ${ }^{1}$ (ECE department, AL-Aman College of engineering/ Jawaharlal Nehru technological university Kakinada, \\ India )
}

\begin{abstract}
Man has gloriously innovated, discovered, profoundly invented some of the state of the art technologies and designed modern structures that stand apart from other civilizations yet there has been growing concern of deteriorating mother earth. Of late, this very dooms day can just be limited to a sci-fi story unlike we approach extra terrestrial life or explore celestial bodies for mineral extraction. Until and unless the very typical and running alternatives are implemented for this desperate eco-friendly transformations.

Human civilization has leaded the path to qualitative technology with greater efficiency than previously used. Yet there has been a demerit for all the technologies that were developed ever since the idea of having technology came. By this we put before you some of the exquisite ways to make use of pristine forces of nature which have been trivialized since the era of modern age.
\end{abstract}

Keywords: $E O, E P G S P, M E, S I E, S T$.

\section{INTRODUCTION}

This paper explains about two working models called simplified traveler and enhanced power generation from solar panel. There are working models partially resembling with the simplified traveler but the ST is far more advanced. The ST is capable of converting solar energy and mechanical energy into electrical energy through three different ways. this simplified traveler travels with the help of three power giving sources which are renewable and non-polluting so that if one fails the other can be used, on the other hand using three power giving sources does not mean of overexploitation, this could be best understood in the future pages of the paper. Enhanced power generation from solar panels, when a solar panel is placed under the sun it converts solar energy into electrical. lets say for example 10 volts can be produced with single solar panel, but through the enhanced power generation we can produce produce 100 volts of electrical energy with the help of 10 concave reflecting surfaces on to the single solar panel. Due to the reflecting surfaces huge amount of light falls on the solar panel and as a result it produces 10 times of its previous out put . [1]

\section{ENERGY CONVERSION EFFICIENCY}

This is a simple definition of efficiency of a device that converts one energy form into another. : -

It is a number between 0 and 1 , or between 0 and $100 \%$. The key word in the definition is useful energy output (EO). Were it not there, the efficiency of any device would be $100 \%$, because of the law of conservation of energy (which states that energy cannot be created or destroyed). Instead, we see that quite a few devices used in daily life have very low efficiencies. The purpose of a device determines its useful energy output. For example, we want light from a lamp, but we get mostly heat; only 5\% of the energy input (electricity) is converted into light, so the efficiency of a conventional incandescent light bulb is $5 \%$.

It is obvious why fluorescent lights are preferable for heavy-duty use (e.g., basements, kitchens, public buildings). Similarly, diesel engines (the kinds used in most trucks and in some cars, especially the European ones) are typically more efficient than conventional spark-ignition engines (SIE) [2]

The familiar term 'fuel economy' or ' mileage' (distance traveled per liter of fuel consumed) is equivalent to the efficiency of an automobile; it is just expressed in different units. Instead of being expressed in units of mechanical energy (work), the useful energy output is given as the average number of kilometers traveled. And instead of being expressed in units of chemical energy, the energy input is given as the number of liters of fuel [3]. Refer figure-(1)

\section{MAXIMUM POWER TRANSWER THEOREM}

Maximum power transfer theorem states that, to obtain maximum external power from a source with a finite internal resistance, the resistance of the load must be equal to the resistance of the source as viewed from the output terminals. The theorem results in maximum power transfer, and not maximum efficiency. If the resistance of the load is made larger than the resistance of the source, then efficiency is higher, since a higher percentage of the source power is transferred to the load, but the magnitude of the load power is lower since the total circuit resistance goes up.[4] 
If the load resistance is smaller than the source resistance, then most of the power ends up being dissipated in the source, and although the total power dissipated is higher, due to a lower total resistance, it turns out that the amount dissipated in the load is reduced. The theorem states how to choose (so as to maximize power transfer) the load resistance, once the source resistance is given, not the opposite. It does not say how to choose the source resistance, once the load resistance is given. Given a certain load resistance, the source resistance that maximizes power transfer is always zero, regardless of the value of the load resistance.[5]

The theorem was originally misunderstood (notably by Joule) to imply that a system consisting of an electric motor driven by a battery could not be more than $50 \%$ efficient since, when the impedances were matched, the power lost as heat in the battery would always be equal to the power delivered to the motor. In 1880 this assumption was shown to be false by either Edison or his colleague Francis Robbins Upton, who realized that maximum efficiency was not the same as maximum power transfer. To achieve maximum efficiency, the resistance of the source (whether a battery or a dynamo) could be made close to zero. Using this new understanding, they obtained an efficiency of about $90 \%$, and proved that the electric motor was a practical alternative to the heat engine[6] .The condition of maximum power transfer does not result in maximum efficiency(ME)

\section{Consider three particular cases:}

The efficiency is only $50 \%$ when maximum power transfer is achieved, but approaches $100 \%$ as the load resistance approaches infinity, though the total power level tends towards zero. Efficiency also approaches $100 \%$ if the source resistance can be made close to zero. When the load resistance is zero, all the power is consumed inside the source (the power dissipated in a short circuit is zero) so the efficiency is zero[7]

\section{LAW OF CONSERVATION OF ENERGY}

The law of conservation of energy states that the amount of energy in a system will stay constant throught time. Therefore this law is stating that no matter how much time goes by, the amount of energy in a certain state of matter will remain the same, hence conserved, no matter how much time has passed. Therefore energy cannot be created nor destroyed but it can be transformed from one form to another form .[8]

A motor is fixed to one of the rod and to the other end of the rod a dynamo is fixed. The axle of the motor is perpendicular to the rod and the same with the dynamo. Now the tires are fixed to the axel of the motor and also to the dynamo. The positive terminal of the motor is fixed to the positive terminal of the dynamo and vice-versa. Let us for a while consider that efficiency of the dynamo and motor in conversion of the given input is only $75 \%$ that means $25 \%$ of the given input is wasted, when input is converted into another form of energy.[9]

Consider an electrical motor and a dynamo of coinciding ratings and parameters, connected to either ends of a supporting rod. However care must be taken that these devices are port vise synchronized (with parallel terminals). let each of these two devices attached with one rotating tire so that it would constitute to a bicycle like movement. Now the arrangement is kept on the ground and is given an initial manual trust which causes the whole arrangement to move forward, because of this moment the dynamo will rotate. It produces 75 $\%$ of electrical energy to which $100 \%$ of input mechanical energy is given (cause of pushing). The $75 \%$ of the electrical output produced by the dynamo is given as input to the motor; it converts its input into $50 \%$ of mechanical energy. As a result the motor rotates the wheel and the whole arrangement moves forward. Again the dynamo rotates and converts its $50 \%$ of the mechanical input into $25 \%$ of electrical out, which is in turn given to the motor, whose mechanical conversion will be $0 \%$. This results in deceleration of the system and finally the system stops. This example proves that conversion of energy involves in wastage of energy and $100 \%$ of energy conversion is not possible.[10] . refer fig-(2) and table-1

\section{SIMPLIFIED TRAVELLER}

There are many vehicles capable of converting solar power into mechanical one and the electrical power to mechanical. The vehicle most popular for electrical power conversion into mechanical energy is Ebike. Due to the limited battery charge, it cannot travel long distances as there are no alternatives except finding a power source (like E-bunks ), therefore the only solution is to be precautious . Now there arises the necessity of having a vehicle which is capable of converting both solar energy and mechanical energy into electrical energy and it should not need any external source to be recharged with in the mid way. This paper puts forward the model called simplified traveler (ST) which possess all the above features.

The simplified traveler is basically a bicycle, with advanced features. The simplified traveler is powered by solar panel, dynamo and simple muscular pedaling so this has three power sources, when one kind of energy source fails the other can be utilized. In this scenario the ST has two alternate power producing sources which under any circumstances can set the ST in motion. For an instance if it's cloudy the solar panel cannot produce sufficient energy to set ST in motion. In this case when ST is pedaled the dynamo also rotates 
which produces energy and is stored in the battery, when peddling is stopped the stored energy in the power storage can be utilized to set the ST in motion.

There has a chain from the pedal and also from the dynamo which is given to the rare twin chain crank wheel which could accommodated two chains .peddling the ST corresponds to the rotation of the dynamo and wheel this results in forward moment of ST and production of electrical energy by the dynamo, this generated electrical energy is stored in the power storage device. If in case the person traveling on ST is unable to pedal then the solar panel can be used.

The simplified traveler is very simple in its working and mechanism. The efficiency of the simplified traveler depends on the kind of dynamo used in producing the electricity when rotated [11].There are different ways to increase the efficiency of the dynamo is

1. by increasing the number windings

2. by increasing the pole strength, magnetic flux density of the magnet

3. by increasing the thickness of the windings refer fig-(3)

\section{ENHANCED POWER GENERATION FROM A SOLAR PANNEL}

This is a simple arrangement of mirrors cut in small uniform dimensions like square. It includes the positioning of such mirrors on to a concave surface which is in turn tilted towards the sun. The arrangement is such that the reflected light from it gets focused on to a particular area. We should arrange a solar panel of high power or any heat conversion energy device.

This arrangement facilitates to produce the same amount of energy from $\mathrm{N}$ number of individual solar panels when compared with a single solar panel assisted by concave reflecting surfaces [9]. As a result the cost of production reduces thousands of times. Because of this arrangement thousands of joules of energy can be concentrated at one point from where thousands of watts of energy can be produced with less loss in energy conversion [12]. Refer fig-(4) (5). Thus EPGSP is very useful in power generation.

VII.

FIGURES AND TABLES

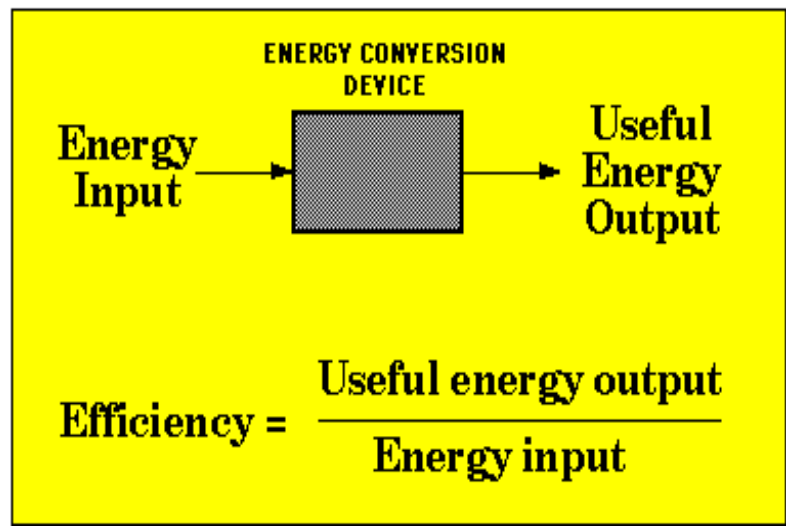

Fig-(1) Efficiency of conversion device.

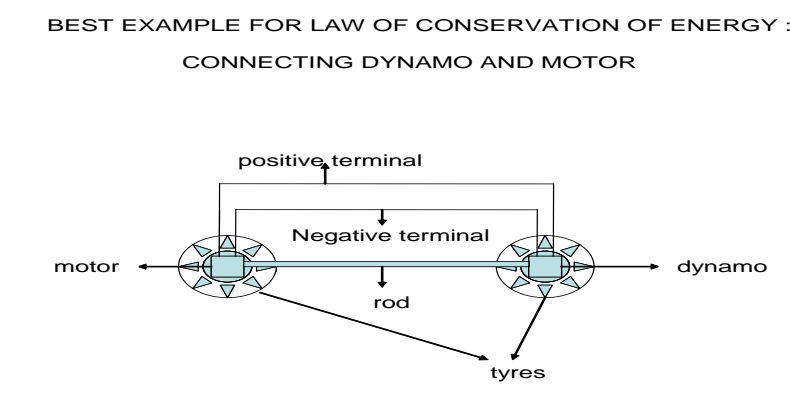

Fig (2): Example for law of conservation of energy. 
MODEL OF SIMPLIFIED TRAVELLER

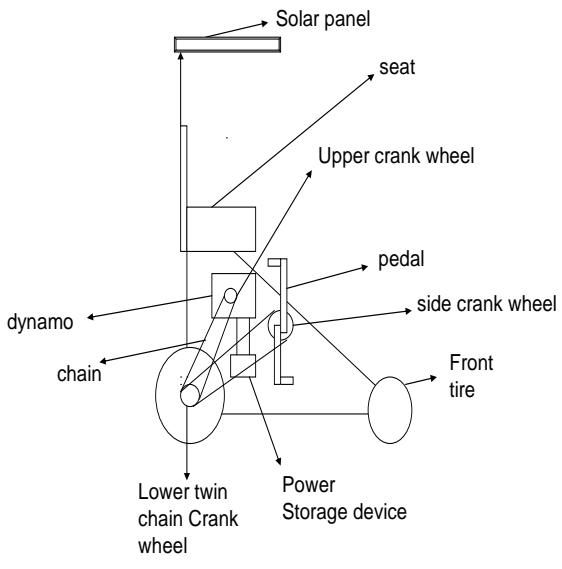

Figure (3): Simplified traveler

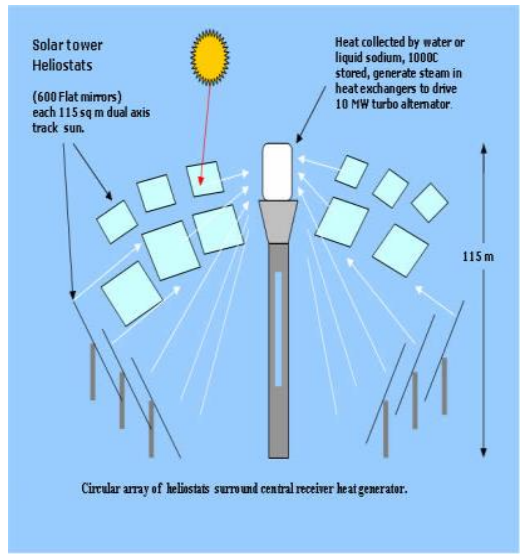

Fig(4): Circular array of reflecting surfaces around solar tower.

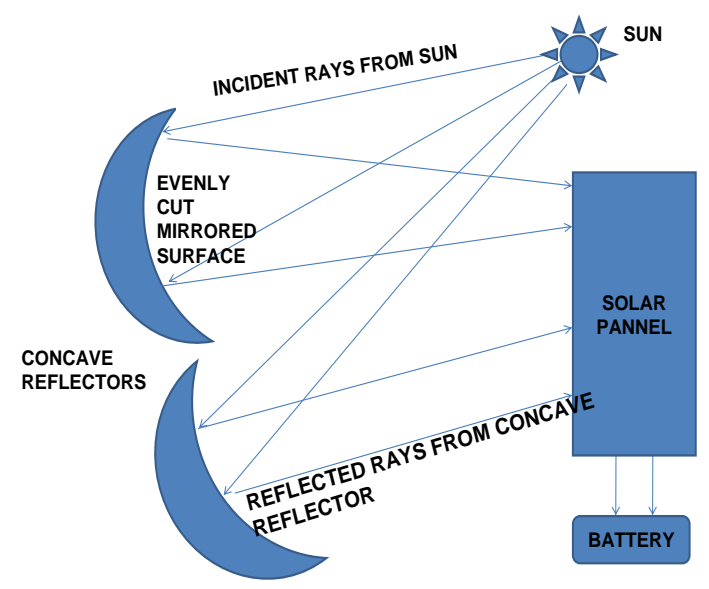

Figure (5): Enhanced power generation from solar panels 


\begin{tabular}{|l|l|l|}
\hline Action & Energy transformation & Outcome \\
\hline $\begin{array}{l}\text { Sun shines on } \\
\text { plants }\end{array}$ & $\begin{array}{l}\text { Light energy from the sun is converted } \\
\text { to chemical energy via photosynthesis }\end{array}$ & $\begin{array}{l}\text { Plants store chemical } \\
\text { energy }\end{array}$ \\
\hline $\begin{array}{l}\text { People eat } \\
\text { food }\end{array}$ & $\begin{array}{l}\text { Stored chemical energy is added to our } \\
\text { bodies }\end{array}$ & $\begin{array}{l}\text { People store chemical } \\
\text { energy }\end{array}$ \\
\hline $\begin{array}{l}\text { Food is } \\
\text { metabolized }\end{array}$ & $\begin{array}{l}\text { Chemical energy becomes av ailable to } \\
\text { muscles, which convert it to kinetic } \\
\text { energy }\end{array}$ & $\begin{array}{l}\text { People can move their } \\
\text { body parts }\end{array}$ \\
\hline $\begin{array}{l}\text { A person turns } \\
\text { the stick of a } \\
\text { wind-up }\end{array}$ & $\begin{array}{l}\text { Kinetic energy gets converted into } \\
\text { elastic energy in the rubber band }\end{array}$ & $\begin{array}{l}\text { The rubber band stores } \\
\text { potential energy, for } \\
\text { later use }\end{array}$ \\
\hline $\begin{array}{l}\text { The person } \\
\text { releases the } \\
\text { wind-up }\end{array}$ & $\begin{array}{l}\text { The elastic energy of the rubber band } \\
\text { gets converted into kinetic energy of the } \\
\text { wind-up }\end{array}$ & $\begin{array}{l}\text { The wind-up trav els } \\
\text { across the floor }\end{array}$ \\
\hline $\begin{array}{l}\text { The wind-up } \\
\text { slows down }\end{array}$ & $\begin{array}{l}\text { The kinetic energy is gradually } \\
\text { transformed into heat energy, due to } \\
\text { friction between the wind-up, and the } \\
\text { floor and air }\end{array}$ & $\begin{array}{l}\text { The wind-up ev entually } \\
\text { stops. The floor, w ind- } \\
\text { up and surrounding air } \\
\text { all heat up very } \\
\text { slightly. }\end{array}$ \\
\hline
\end{tabular}

TABLE 1: Energy transformation table

VIII.

SIMULATION RESULTS

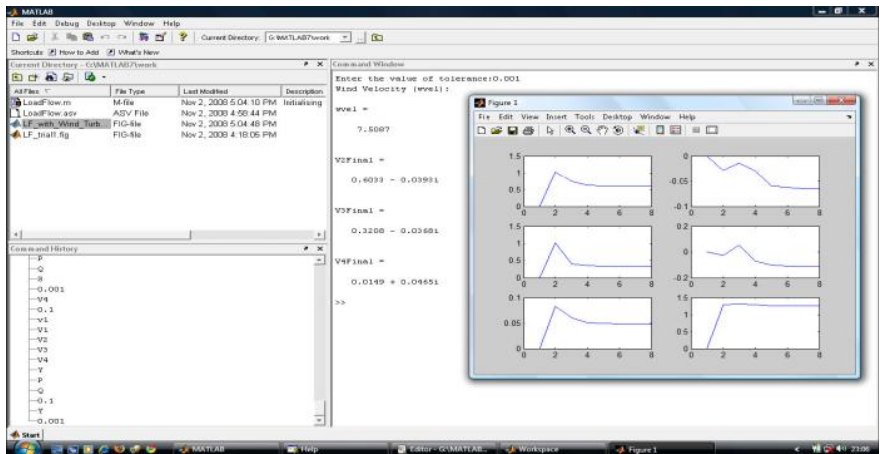

Fig (6): output voltage of a solar panel

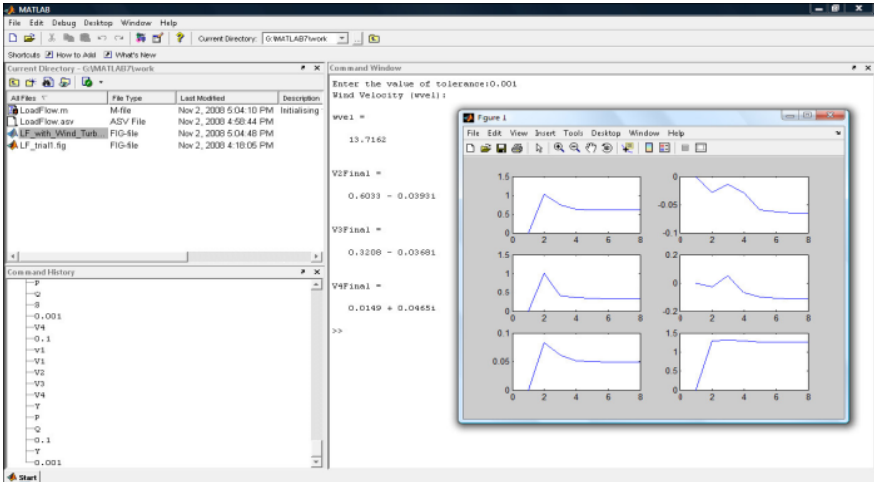

Fig(7): out put voltage of a motor

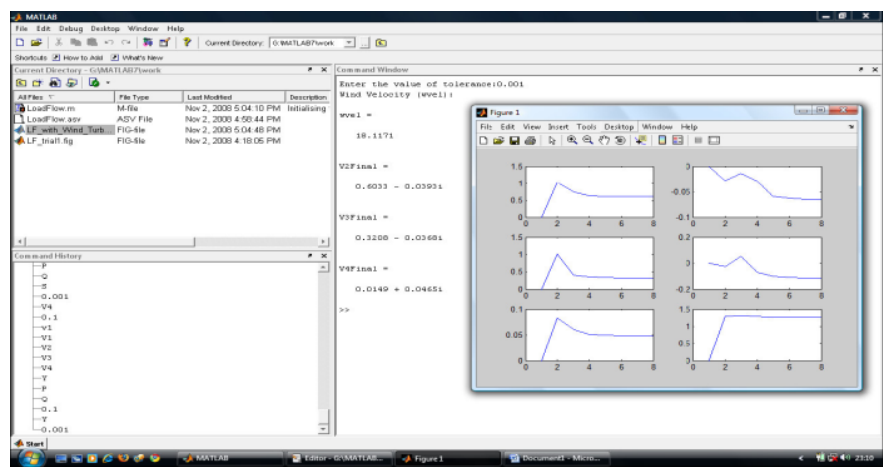

Fig(8): out put voltage of a dynamo

www.iosrjournals.org 


\section{CONCLUSION}

The paper finally explains the utilization of renewable energy resources, in the way that they do not pollute the environment. More over the simplified traveler can be used and constructed with less effort, the only limitation of the ST is more number of people cant travel on it at once. The enhanced power generation from solar panel helps in producing power at higher rate with the help of a single panel. This reduces the usage of more number of solar panels to produce the same amount of energy which is obtained with the help of the enhanced power generation from the solar panel

\section{REFERENCES}

[1] Georg Hille, Werner Roth, and Heribert Schmidt, “Photovoltaic systems,' Fraunhofer Institute for Solar Energy Systems, Freiburg, Germany, 1995.

[2] OKA Heinrich Wilk, "Utility connected photovoltaic systems," contribution to design handbook, Expert meeting Montreux, October 19-21, 1992, International Energy Agency (IEA): Solar Heating and Cooling Program.

[3] Stuart R. Wenham, Martin A. Green, and Muriel E. Watt, “ Applied photovoltaics,' Centre for photovoltaic devices and systems, UNSW.

[4] N. Ashari, W. W. L. Keerthipala, and C. V. Nayar, "A single phase parallel connected Uninterruptible power supply/Demand side management system," PE-275-EC (08-99), IEEE Transactions on Energy Conversion, August 1999.

[5] C. V. Nayar, and M. Ashari, "Phase power balancing of a diesel generator using a bidirectional PWM inverter,' IEEE Power Engineering Review 19 (1999).

[6] C. V. Nayar, J. Perahia, S. J. Philips, S. Sadler, and U. Duetchler, “'Optimized powerelectronic device for a solar powered centrifugal pump,'Journal of the Solar Energy Society of India, SESI Journal 3(2), 87-98 (1993).

[7] Ziyad M. Salameh, and Fouad Dagher, "The effect of electrical array reconfiguration on the performance of a PV-powered volumetric water pump," IEEE Transactions on Energy Conversion 5 653-658 (1990).

[8] C. V. Nayar, S. J. Phillips, and W. L. James, T. L. Pryor, D. Remmer, "Novel wind/diesel/battery hybrid system,"' Solar Energy 51, 65-78 (1993).

[9] W. Bower, "Merging photovoltaic hardware development with hybrid applications in the U.S.A.' Proceedings Solar '93 ANZSES, Fremantle, Western Australia (1993).

[10] Carlson, D. E. 1995. "Recent Advances in Photovoltaics," 1995 Proceedings of the Intersociety Engineering Conference on Energ y Conversion 1995, p. 621-626.

[11] www.google.com

[12] www.en-wikipedia.org 